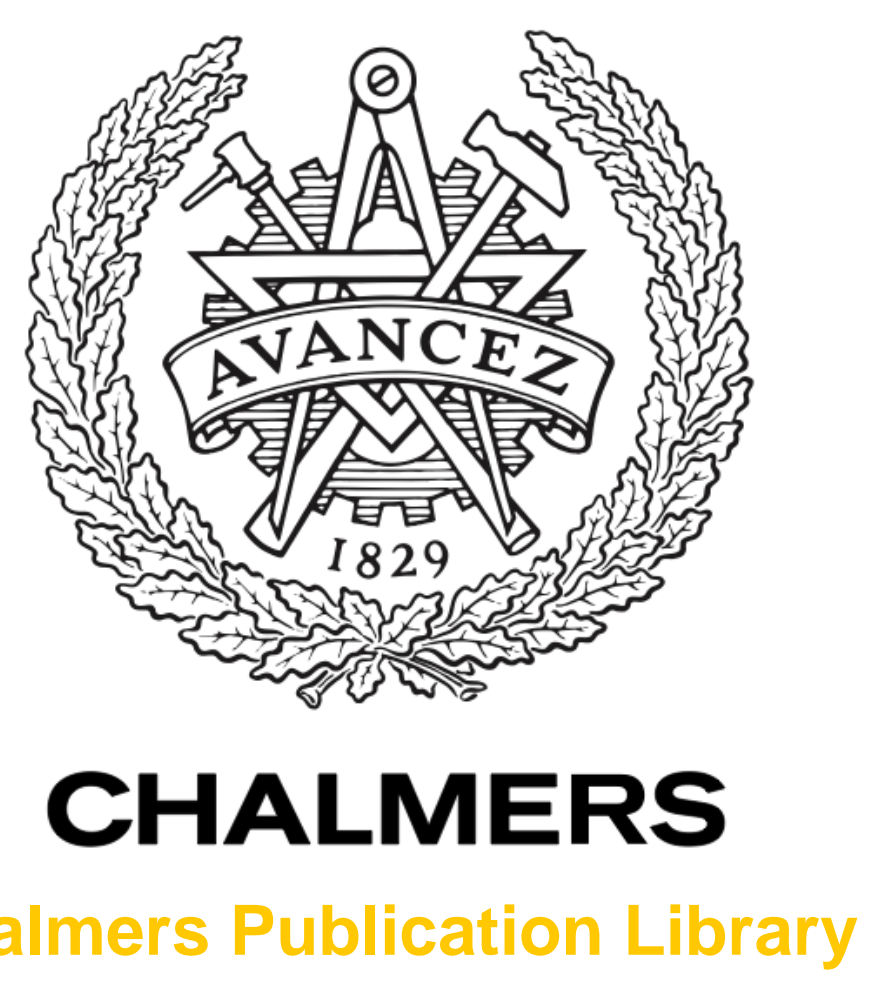

Chalmers Publication Library

A model for linking shop floor improvements to manufacturing cost and profitability

This document has been downloaded from Chalmers Publication Library (CPL). It is the author's version of a work that was accepted for publication in:

International Journal of Computer Integrated Manufacturing (ISSN: 0951-192X)

Citation for the published paper:

Sundkvist, R. ; Hedman, R. ; Almström, P. (2012) "A model for linking shop floor improvements to manufacturing cost and profitability". International Journal of Computer Integrated Manufacturing, vol. 25(4-5), pp. 315-325.

http://dx.doi.org/10.1080/0951192X.2011.608725

Downloaded from: http://publications.lib.chalmers.se/publication/159942

Notice: Changes introduced as a result of publishing processes such as copy-editing and formatting may not be reflected in this document. For a definitive version of this work, please refer to the published source. Please note that access to the published version might require a subscription.

Chalmers Publication Library (CPL) offers the possibility of retrieving research publications produced at Chalmers University of Technology. It covers all types of publications: articles, dissertations, licentiate theses, masters theses, conference papers, reports etc. Since 2006 it is the official tool for Chalmers official publication statistics. To ensure that Chalmers research results are disseminated as widely as possible, an Open Access Policy has been adopted.

The CPL service is administrated and maintained by Chalmers Library. 


\section{A model for linking shop floor improvements to manufacturing cost and profitability}

Sundkvist, Robin ${ }^{1}$ Hedman, Richard ${ }^{1}$ Almström, Peter $^{1}$

${ }^{1}$ Department of Materials and Manufacturing Technology, Chalmers University of Technology, Gothenburg, Sweden

Robin Sundkvist

Phone: +46(0)31-772 1312

Mobile: +46(0)70-224 1198

robin.sundkvist@chalmers.se

*Richard Hedman

Phone: +46(0)31-772 1312

Mobile: +46(0)73-610 4440

richard.hedman@chalmers.se

Peter Almström

Phone: +46(0)31-772 1283

Mobile: +46(0)76-101 0567

peter.almstrom@chalmers.se

Postal address:

Department of Materials and Manufacturing Technology

Chalmers University of Technology

SE-412 96 Gothenburg

*Corresponding author 


\section{A model for linking shop floor improvements to manufacturing cost and profitability}

Manufacturing units in so called high-cost countries are struggling under fierce competition on the global market. In order to survive, the factory needs to generate profit to its owners. Profitability can be reached in many different ways apart from only lowering the employees' salaries. It can be improved through increased profit margins (sales in relation to costs) or with an increased capital turnover rate. Finding ways to free capacity and to improve flexibility in order to increase sales is often more interesting to the manufacturing companies than cutting the direct salary costs.

A model for analysing profitability of a manufacturing unit is proposed. It is found on a production system analysis and combines in-depth production engineering analysis with economical accounting analysis of the factory. The manual work tasks are of special interest and the productivity of selected bottleneck work areas are analysed thoroughly. The model is intended for use by two industrial analysts during a one-week study. Simulation of different improvement scenarios is carried out and presented to the factory management at the end of the profitability study. A software implementation is required in order to generate the model, collect data, and make simulation within the intended time.

The implementation is made in spread sheet software using Visual Basic to program interfaces and automatic functions. The primary area of application is the electronics industry in Sweden where the model is used in a research project to strengthen the competitiveness of that industry.

Keywords: Productivity analysis, profitability analysis, manufacturing cost model

\section{Introduction}

Comprehensive investigations of the shop-floor productivity potential in the Swedish manufacturing industry have been carried out in the Productivity Potential Assessment (PPA) studies (Almström and Kinnander 2011). The PPA method focus on analyzing productivity potential through measurements and assessment by industrial analysts during a one-day study of a factory. This analysis can be used either for benchmarking or as a pre-study for an improvement program. However, increasing productivity is just an intermediate goal. The ultimate goal for any commercial operation must be to generate profitability, return on investment or assets, 
to its owners. The underlying rationale for this article is that many companies do not know how their production systems contribute to the organizations' profitability.

This article present a model for translating and simulating operational improvements, in terms of cost decrease, output increase, and less working capital, to profitability for a manufacturing company. The purpose of the model is to be able to collect all in-data, make the analysis, simulate the effect on profitability, and finally demonstrate the simulation for the factory management, after only one week's job by two consultants or other external analysts. The analyzed factory's own personnel is used to gather information and generate improvements ideas, but not an extent where it will affect the normal operation of the production unit. The idea is to find possible operational improvements and to simulate the effect of these improvements in different scenarios for the management. The primary area of application is the electronics industry in Sweden, where the model is used in a research project aiming to strengthen the competitiveness of that industry. The model has been developed and tested in four different factories in the electronics industry so far.

Before the profitability model is outlined and discussed, a literature review of alternative models is presented. The review is followed by the theoretical background of productivity improvements and other production engineering improvements at shop floor level, and the economic theory needed to build the model.

\section{Linking operational effects to financial effects}

There are many ways to approach the problem of linking operational performance to financial effects. A common way is to apply performance measurement systems (PMS) to assess and evaluate both micro perspectives (productivity and efficiency in operations) and macro perspectives (performance at corporate level). Operations 
management literature presents a vast collection of methods and methodologies for this purpose (Neely 2005). One of the most cited and widely adopted method is the balance scorecard (BSC) presented by Kaplan and Norton (1992). The idea of the BSC is to apply a balanced set of measures that allow managers to monitor four important management perspectives (financial, internal business, customer, and innovation and learning) in order to align operational actions with strategy (Geert and Nijssen 2004). Kaplan and Norton (2008) claim that most companies underperform due to breakdowns between strategy and operations. Depending of what perspective stakeholders possess, financial (e.g. shareholders) or internal business (e.g. operations managers), their objectives of improvements are different. A common conflict between these stakeholders is dividends to shareholders, which consequently reduce the amount of resources under operations managers' control (Jensen 1986).

The PMS literature covers both financial and non-financial measures. Depending of their context, their meaning may differ. In the case of operations, nonfinancial measures often refer to specific activity performance such as speed, flexibility and delivery precision (Slack et al. 2010). From a financial point of view, non-financial measures often refer to intangibles such as brand value, quality of management, human capabilities and customer relations (Low and Siesfeld 1998). Financial measures however, do more or less have the same meaning regardless of context and they are publically available. A manufacturing company has no commitment to present internal operations performance in terms of e.g., delivery precision, yield (quality) or lead time (speed) to the public. A result is that market participants cannot value internal operations, neither the hidden potential in a firm's operations, as they can with financial performance. 
A manufacturing firm's earnings are based on its product and service offer. In order to promote the most profitable products and possibly terminate the least profitable products, profit contributions of each product need to be understood. This area of analysis is related to accounting systems. Typical decisions that the accounting systems facilitates are for instance, make or buy decisions, product pricing, and supplier selection (Boyd and Cox 2002). The relevance of the cost information provided by these systems is arguably one the most important objectives of cost accounting (Boyd and Cox 2002). The common conception is that standard costing methods, where overhead costs are equally allocated to all products produced, are obsolete due to technology and market development (Kaplan and Cooper 1998). That is, direct costs have decreased in proportion to indirect costs each affected by different cost drivers resulting in misleading cost information given by standard costing systems. To facilitate managerial decisions and overcome the deficiencies of standard costing, systems such as activity based costing (ABC) and throughput accounting based on the theory of constraints (TOC) were developed. Throughput accounting considers throughput (revenues generated through the production of sold goods), inventory and operating expenses as three important performance measures (Sheu et al.2003). ABC instead, strives to provide detailed information of activity and resource consumption throughout the organization to allocate these to cost objects such as products or transactions. One of the main differences of these systems is the time aspect. TOC is regarded as a short term cost behaviour model based on given constraints while $\mathrm{ABC}$ is referred as a long term cost behaviour model based on resource usage (Sheu, Chen and Kovar 2003). Consequently these mentioned cost systems influences a firm's strategic objectives and subsequently a firm's investment 
decisions and how operations are managed. The objective of the proposed analysis model is not however, to assess strategic management thinking, nor advocate a certain strategic mind set. The goal is instead to cost efficiently describe and understand a firm's hidden potential in currently used human and technology capabilities, and how they can be used in the future to increase profits. The ABC model is suitable for this purpose due to its inherent objective of describing a firm's resource utilization.

The initial ABC model however, has undergone some development since it became public available in the mid-1980s. Some of the drawbacks of traditional ABC accounting are stated as (Kaplan and Anderson 2007):

- The activity analysis, carried out as interviews and surveys, is timeconsuming and costly and, the input data collected during the activity analysis is subjective and difficult to validate.

- The $\mathrm{ABC}$ data is expensive to store, report and process.

- $\mathrm{ABC}$ models are commonly used locally and do not provide an integrated view of profitability opportunities.

- $\mathrm{ABC}$ models ignore the potential of unused capacity.

To deal with these problems, time-driven (TD) ABC was introduced to virtually skip the difficult activity analysis stage. Instead TDABC uses two parameters, capacity cost rate and capacity usage for describing transactions processed in a certain function or department (Kaplan and Anderson 2007). An important aspect of the TDABC approach is that it uses dynamic calculations of capacity, transferring them on costs and thus distinguishes between practical and total capacity costs (Ayvaz and Pehlivanli 2011). This distinction is an important part of the model presented in this article. 
It is widely recognized that product costs are influenced at most in early stages e.g. conception, design and development (Hundal 1997; Chougule and Ravi 2006; Park and Simpson 2005). Hundal (1997) refers to this as "the designer's paradox" meaning that the ability to influence product cost is at its highest during design and development while at the same time available cost information is at a minimum. It is however important for a company to know the manufacturing costs since it is the major part of the total cost (Hundal 1997). Chougule and Ravi (2006) presents several cost estimation approaches that can be categorized as either qualitative or quantitative. For instance, intuitive and analogical approaches are qualitative and are based on past experience of the estimator or comparison of a new product with similar existing products. In practice, Niazi et al (2006) have listed some available intuitive cost estimation techniques e.g. Case-Based Methodology and also different decision support systems divided into three subcategories: rule-based systems, fuzzy-logic approach and expert systems. Examples of analogical techniques, using only historical data, are regression analysis cost models and Back-Propagation Neural-Network Models.

Quantitative methods, such as parametric and analytical approaches, are based on analysis of both product design and the corresponding manufacturing processes (Niazi et al. 2006; Chougule and Ravi 2006). In the time-driven ABC, costs are determined by elementary activities, e.g. setup, machining, assembly etc. However, Niazi et al. (2006) also presents similar analytical techniques such as operation-based approach, breakdown approach, tolerance-based cost models and feature-based cost estimation.

Except for spin offs or development of the balanced scorecard, for example Kaplan and Norton's proposal for a closed-loop management system (Kaplan 
andNorton 2008), which is a combination of several methods; few references have been found in the area of how the production system contributes to profitability and growth. Thus, by providing a cost effective method, based on an existing productivity assessment tool, productivity potential assessment - PPA, and the DuPont schematics, a link can be established between financial outcome (profitability) and operational shop floor performance.

\section{Productivity and shop floor improvements}

Productivity is a well-known and established term in the manufacturing industry. It describes the relationship between the products being produced and the amount of resources being used in the transformation process (Bernolak 1997). Thus, productivity is commonly defined as output (e.g. number of assembled cars, computers, or speakers) divided by input (e.g. per time unit, per employee, or per capita) (Tangen 2005). For manufacturing activities, productivity or productivity improvement can be expressed as equation 1 and 2 (Saito 2001, Sakamoto 2010, Almström and Kinnander 2011). Equation 1 is valid for manual activities (operations with manual work content) and equation 2 is valid for automatic activities (operations performed by machines).

$$
\begin{aligned}
& \text { Productivity }=\text { Method }(M) \times \text { Performace }(P) \times \text { Utilization }(U) \times \text { Quality }(Q) \\
& \text { Productivity }=\text { Method }(M) \times \text { Overall Equipment Efficiency }(O E E)
\end{aligned}
$$

The $\mathrm{M}$ factor (equation 1 and 2) is the productivity measure of an individual operation or activity performed at the shop floor. An example is "number of assembled objects per time unit". The M value for manual operations is determined by a pre-determined time system such as Methods-Time-Measurement (MTM) 1, 2, or 3 (Niebel and Freivalds 2004) or the Sequence Based Activity and Method Analysis 
(SAM) (IMD 2004). The M value for machine operations is usually calculated in process planning activities using Computer Aided Manufacturing (CAM) software and various simulation tools. By using a pre-determined time system, it is possible to provide each operation within a production system with a standard time. In addition to offering a given standard time, a method study will also make it possible to compare a current state with a proposed future state, i.e. establish a future state $\mathrm{M}$ value based on operation improvements. An example of improving the $\mathrm{M}$ value is to change from a manual screwdriver operation to an electrical screwdriver operation. The operation may be ten times more efficient because of the change in method. The improvement can be visualized and understood quantitatively by comparing the productivity ratio before and after the change. However, the introduction of the screwdriver also represents an investment. Improvements of $\mathrm{M}$ will often result in a need for investments. The exception is smaller method changes, like excluding unnecessary steps by moving material closer to the work area.

The $\mathrm{P}$ factor in equation 1 refers to the speed that the activity is carried out at in practice. The performance rate is determined by comparison with normal speed. Normal speed for manual work is defined by an accepted predetermined time system like MTM (Niebel and Freivalds, 2004). The normal speed is set at a level that is ergonomically acceptable for the average operator. Performance losses are usually a matter of lack of skills or motivation.

The $\mathrm{U}$ factor in equation 1 equals the portion of the planned production time that actually has been used to create value for the customer. For example, if the planned production time for a manual work operation is set to 60 hours per week and the actual production time is only measured to be 30 hours per week, the utilization parameter is set to $0.5(50 \%)$. Common utilization problems are long set-up times, 
adjustments, breakdowns, idling and small stops. The $U$ factor for manual work is measured through a work sampling study (Niebel and Freivalds 2004).

The $\mathrm{Q}$ factor in equation 1 refers to the yield of a specific production process. Only the scrap rate is of importance since re-work is considered as waste contained in the $\mathrm{U}$ factor. For example, if one out of ten products needs to be scrapped due to insufficient precision in a manual assembly process, there is a potential to reduce the direct material costs by $10 \%$ and increase output at the same time.

For automatic activities, factors $\mathrm{P}, \mathrm{U}$ and $\mathrm{Q}$ in equation 1 are included in the overall equipment efficiency OEE value (equation 2). This value requires such machine data as actual run time, power on time, operations cycle times etc. The OEE analysis has several definitions (Muchiri and Pintelon 2007) but is used in this profitability model as the total preventive maintenance (TPM) literature describes it (Nakajima 1988).

\section{Profitability relationships}

Profitability refers to a firm's financial performance rather than its operational performance. Profitability is what the top tier stakeholders, i.e. the owners, of the company primarily care about (Slack et al. 2010). What drives a firm's profitability can be argued, but it is clear that it is affected by both controllable and uncontrollable factors (Pehrsson 2000). The global economy and political environment surrounding the company are examples of uncontrollable factors. Controllable factors are found to be a firm's resources in terms of energy, material and human capital etc. (Alsyouf, 2007). 


\subsection{Profitability analysis}

There are many definitions of profitability, such as Return on Investment and Return on Equity. In this model Return on Assets (ROA) is used as the profitability measure (equation 3).

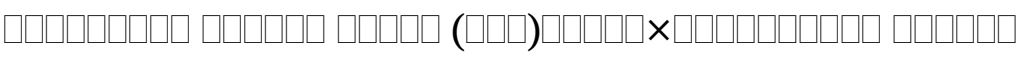

Consequently, a company can increase profitability in two ways: either by increasing profit margins (EBT divided by sales) or by increasing capital utilization (sales divided by total assets).

Increased profit margins are reached by producing more with same amount of resources or, alternatively, by raising prices. Both alternatives are market driven. A third option for increasing profit margins is to utilize fewer resources, i.e. to cut costs. A fourth way of improving profitability is to utilize the company's assets more efficiently by reducing the amount of capital tied up in assets. The definition of ROA is derived from the classical DuPont model (figure 1).

Figure 1. Profitability relationship (return on assets) between price, cost, sales and assets.

\subsection{Cost allocation}

The input data used to analyse the $R O A$ ratios can be found in the annual report of the studied company. However, the consolidated figures in the annual report contain too much information to be used as direct input in a model. Since companies use different accounting systems, all data must be converted into a standardized format that fits the profitability model.

From the income statement, costs are allocated to the costs groups described below:

- Direct salary (DS): Cost for personnel adding direct value to the products being produced. 
- Direct material (DM): Cost for material used in the products produced.

- Material overheads (MO): Cost for material handling personnel and equipment used for support operations.

- Production overheads (PO): Machines and other manufacturing equipment used to produce value.

- Others (OC): All other costs for supporting the production system, such as production development, planning and control, administration etc.

\subsection{Productivity - cost relationship}

The productivity relationship shown in equations 1 and 2 does not involve the term cost, which is essential in order to connect productivity measures with financial measures such as ROA. According to the activity based costing literature (Ong 1995; Özbayrak et al. 2004), each activity carried out on the shop floor consumes a resource, e.g. energy, labour, materials etc. Each resource can thereby be described in financial terms by a certain cost driver, for example:

- $\quad$ Labour cost $=$ Salary per time unit

- Machine cost = A specific machine cost per time unit

- Energy cost $=$ Kilowatts used per time unit

A productivity relationship such as equations 1 and 2 may, in combination with the amount of planned production time, describe an operation's capacity in terms of output produced per time unit. If a cost driver is added to each of the operations, it will be possible to calculate a cost per time unit.

\subsection{Capital allocation}

The income statement only provides information about costs and sales. To analyse how capital is tied up in products and machines, i.e. the company's assets, data from the balance sheet must be considered. The balance sheet can be simplified into two 
parts, liabilities (assets) and debts. From a production point of view, debts are not of interest since the production system does not affect them directly. The assets can be divided from a production point of view into materials, buildings, and machines. All three can be affected by production engineering improvements.

\section{Profitability model}

In this section it is described how the profitability analysis model is designed to represent an actual production system. A system hierarchy definition is presented in table 1. Levels three to five in table 1 are based on the SAM definition (IMD 2004).

Table 1: Production system definition

\begin{tabular}{|c|c|c|}
\hline Level: & Name: & Description: \\
\hline 1 & System & The production facility. \\
\hline 2 & Subsystem & $\begin{array}{l}\text { A defined area of the production facility (level 1), e.g. } \\
\text { the storage area, the painting area or the assembly } \\
\text { area etc. }\end{array}$ \\
\hline 3 & Operation & $\begin{array}{l}\text { A specific activity performed in the subsystem (level } \\
\text { 2), } \\
\text { e.g. assembly, inspection or testing etc. }\end{array}$ \\
\hline 4 & Sub-operation & $\begin{array}{l}\text { A specific part of an operation (level 3) containing a } \\
\text { sequence of elements (level 5). For example count } \\
\text { components, put components in box, deliver box to } \\
\text { position A to B. }\end{array}$ \\
\hline 5 & Element & $\begin{array}{l}\text { An individual activity performed in the sub- } \\
\text { operation, e.g. get, put or use etc. }\end{array}$ \\
\hline
\end{tabular}

The concept for the integrated profitability model is depicted in figure 2 . The general production system analysis made through PPA is combined with the in-depth productivity analyses of the selected work areas and the accounting analysis. All the potential improvements that the analyses result in will affect the system on the different system levels. The different system levels ties the potential improvements to the DuPont schematics, thus the profitability for different improvement scenarios can 
be simulated. The relationship between improvements and economical effect is complex, and consequently the greatest challenge to master in the model.

Figure 2. The concept for the integrated profitability model.

The model is intended for analysis of one factory. It would be too extensive and time consuming if all subsystems, and their adherent operations, were to be included when performing profitability analysis. The analysis must be focused on the subsystem that is considered to be the system bottleneck. Every system must have at least one constraint (Dettmer 1997; Raham 1998). However, the model is not limited to studying only the system's bottleneck. Improvement potential linked to profitability is also found in other areas, not being a direct capacity constraint, e.g. subsystems with high costs or a large amount of WIP. In the model it will be possible to generalize findings in the selected subsystem to similar subsystems in the factory. One product or a product family is selected for the in-depth activity analysis. The product selection is foremost made by the studied company's management based on their conception of which the most important products or product families are for the company. The Pareto principle or the ABC analysis (Chen et al. 1993), not to be confused with $\mathrm{ABC}$ as in Activity Based Costing, can be used for the selection. In the $\mathrm{ABC}$ classification tems are categorized according to monetary value and amount (volume), into A, B, and C categories (Flores and Whybark 1986; Flores et al. 1992; Chen et al. 1993). This is a strict cost-volume criterion for prioritizing products and components. However, Flores and Whybark (1986) presents additional categories that may be taken into consideration e.g. lead time, criticality, commonality, obsolescence, substitutability and reparability, where lead time and criticality are identified as the most important categories. This support the practice of letting the management make 
the selection based on their perception of importance. In a production system there are a lot of interdependencies that are not obvious or generally predictable. A side effect of applying the model is that these interdependencies will be analysed and questioned at each studied company. An expert knowledge will be gradually built to handle this and making the simulation experiments more accurate.

\section{Model design using Microsoft Excel and Visual Basic for Applications}

The system architecture of the profitability analysis model is based on Microsoft Excel spreadsheets which facilitates a structural representation of input and output data. Visual Basic for Applications (VBA) is used to partly automate three major tasks; building the model, performing simulation and displaying results. Each task is built by VBA modules based on procedures and functions, also using Excel standard functions and analysis tools. The modules are stored in a customized template workbook with a graphical user interface that allows the user to build models of different systems that follows the defined system hierarchy presented in table 1 .

\subsection{Build model}

Collection of input data is done prior to building the model. There are two different identities of input data. First, financial input data which constitutes the analyzed company's balance sheet and income statement translated using the cost and capital allocation described in section 3. Second, operational input data constituting the productivity relationships shown in equations 1 and 2 are the results from the production engineering and productivity analysis. Reading of input data to the model can be done in two ways; either a procedure asks the user to select a range of data, or the data is entered manually via a user form. This describes what was stated as "partly automated tasks" in the paragraph above, meaning there is a need for continuous user interaction when input data is selected. 
The user interface of the workbook template presents a work sequence of how a system model is built. The work sequence has three predefined VBA routines presented in figure 3 "Build system" and figure 4 "Build subsystem and Build operation". The VBA routines are designed so that the system model is built iterative. Meaning, after the user has initiated the model and its system parameters the number of studied subsystems is specified, as can be seen in figure 3 . Subsequently there is a jump to the VBA routine "Build subsystem" in figure 4. Analogous, when subsystem parameters have been specified and corresponding number of operations for that subsystem has been entered there is a jump to the routine "Build operation", also in figure 4. Once all operations for one subsystem have been built there is a jump back to the "Build subsystem" routine and the subsystem output is calculated. The final jump back to the "Build system" routine is done after models of all studied subsystems have been generated.

Figure 3. Flowchart representing the main process "Build system".

Figure 4. Flowcharts displaying the sub processes of building subsystem and operations.

Costs, assets and sales are used as input for defining the system parameters. They represent the system's sum of costs, assets and sales. When a system model is complete, interdependencies between operations, subsystems, and system parameters have been determined and the parameters can then be used as input data to the DuPont model during the simulation approach when the model is complete.

The labour force demands salaries, and machines demands services, energy and investments, which are all related to costs. Figure 4 shows how each studied 
subsystem uses cost distributions and assets, allocated from system level, to determine subsystem parameters. Data inputs to operations consist of the M, P, U and Q parameters (OEE for automatic operations) together with amount of staff per operation and average cost per person.

\subsubsection{Creating links from operational to system level}

In the proposed model with defined links between operational parameters and system parameters are presented in figure 5. Grey fields of input and output data represents ranges in Excel. Stored data is taken from the accounting system, the income statement and the balance sheet and is transformed manually into several ranges using the standardized cost and capital allocation described earlier. Operational data is the result of factory floor productivity studies.

Figure 5. Data flow diagram connecting operational and financial input data to linked system parameters.

The predefined procedure "Calculate operation output" uses a range of operational data together with a range of financial allocated data to calculate specific output for each operation. As stated, the operations are carried out by some kind of resource, either an operator or a machine, or by a combination of both. These resources are all subjects of costs and are on an operation level measured in direct salary, machine cost, and material waste. Real capacity is calculated based on productivity relationships in equation 1 and 2 .

Thereafter the procedure "Calculate subsystem output" uses ranges for all of the subsystem's "Operation specifics" together with the financial allocated data. A subsystem's capacity is determined by its constraining operation. The cost distribution is a sum of each operation's cost along with financially allocated costs on a subsystem level. Finally, the subsystem's influence on the total system is determined based on 
the ratio between the subsystem's costs and assets and the system's total costs and assets.

In this model the key to create links from operation to system level is to work with ranges of input and output data in the spreadsheet. VBA code does not need to select a range in order to work with it. This makes the template flexible since it is possible to study an optional number of subsystems with different sets of operations.

\subsection{The simulation approach}

Once a system model is built the user interface allows next step to be executed. A simulation of operational improvement and their effect on cost and profitability is conducted using one of Excel's built in What-if analysis tools; the Scenario Manager. Each scenario is a named combination of values assigned to one or more variable cells in the system model. In the proposed model those variable cells are referred to as simulation variables and it is up to the user to determine what variables that is to be included in the simulation. In future application, with increased experience from using the model, it will be possible to use predefined sets of simulation variables. It will also be possible to introduce stochastic variables to add a dynamic dimension to the analysis. In that case, the simulation experiments may be carried out in discrete event simulation (DES) software. There are efforts made to link production system dynamics via DES to a manufacturing costs estimation (Jinks et al. 2010).

\subsubsection{Choosing simulation variables and result cells}

Shop floor improvements are directly related to improving one or more of the operational parameters described in equations 1 and 2 . These shall be chosen as simulation variables. Further cost changes, on a subsystem level, can be simulated by adding an extra variable in each cost distribution. Thereby, by making different 
assumptions based on improvement suggestions from the initial productivity studies the user can choose to change the subsystem's cost distributions.

In total up to 32 simulation variables can be chosen per scenario (a limitation in Excel). Since links have been established when building the model changing the simulation variables will affect the final system parameters cost, assets and sales. The final system parameters are also input data when calculating the ROA ratio using the DuPont model.

\subsubsection{Presenting the results}

Based on the simulation variables several scenarios can be created. The different scenarios are compiled by Excel as a scenario summary report or a scenario pivot table report. Changing simulation variables in each scenario will not affect the original values in the cells. The user has to specify what result cells that should appear in the report. Naturally, the ROA ratio from equation 3 should be chosen as a result cell. However, there is a possibility to include more result cells in the report.

\section{Discussion}

There are several difficulties in both the data collection and in building the relationships in the simulation model. Some of the issues are discussed in this section. The productivity study will give accurate results, i.e. defined and validated $\mathrm{M}$ values for the specific product being produced at the time of the analysis. Different products may demand different amounts of resources, which will generate different $\mathrm{M}$ values for similar operations. Thus, a method analysis of one product may not be valid for other products even though they are processed in the same operations. If the work content within the operations differs between different products, one approach is to analyse several products to get a mean $\mathrm{M}$ value representative for a specific type of products, e.g. the most produced products or the most valuable products etc. Another 
approach might be to delimit the simulation to only be valid for on product or one group of products. To make the calculations more accurate TDABC (see section 2) might be used to formulate time equations for different products or product families.

If a company is striving to increase its capacity (output improvements), it cannot be certain that subsystems other than those analysed in the study can handle the suggested capacity improvements without increased costs. On the other hand, cost reduction actions can in some sense always be realized since they do not demand anything further of the production system. Thus, it is more accurate to simulate cost reduction actions rather than capacity improvements in sub-systems not analysed in detail in the study. For example a utilization loss caused by organisational and managerial factors may very well be universal for all subsystems.

The model is also restricted in terms of what can be converted into monetary units. For example a production improvement resulting in using fewer resources (labour, material or energy etc.) can directly be converted into monetary units. However, a specific improvement may also lead to other combined improvements, such as easier planning, improved work environment or improved labour relations. These types of combined effects are difficult to translate into quantitative entities, but may in many cases be the key success factor for increased profitability. The experienced analyst may make a qualified estimation of the economic effect, but the accuracy will be low.

The financial data used as input to the model come from the annual report and data from the company's accounting system. These accounting systems may vary between companies, rendering difficulties in creating a standardized financial data collecting format. The financial condition of a company is also under continuous change because of labour turnover, customer turnover and changes in the surrounding 
environment. The annual report is a snapshot of a specific point in time (December $31 \mathrm{st})$. Thus, financial data from the annual report may give a misleading picture of the company's financial situation as compared with the current condition. To cope with these problems, it is suggested to use the latest, monthly or quarterly closing of the accounts as input to the model.

In a production system there are a lot of interdependencies that are not obvious or generally predictable. A side effect of applying the model is that these interdependencies will be analysed and questioned at each studied company. An expert knowledge will gradually be built to handle this and making the simulation experiments more accurate in the profitability model.

\section{Conclusions}

By combining production engineering with accounting and financial analysis a model for linking shop floor improvements to manufacturing cost and profitability has been developed. The model is cross-disciplinary and will serve to ease the communication between production engineers or shop-floor personnel in general, and the management or the owners of the company.

The purpose of the proposed model is to visualize how productivity improvement actions affect a firm's profitability. Owners take financial risks when they invest capital in actions to improve productivity. They are willing to take risks since they expect a return on their investments. The model motivates and increases owners' willingness to make investments since it visualizes how, and to what extent, improvement actions lead to improved profitability.

\section{Future research}

As discussed earlier, it is difficult to simulate how shop floor productivity improvements affect non-value adding but necessary activities such as planning and 
other support functions. More research is needed to be able to understand how combined productivity improvements are related to profitability. The objective is to find general relationships between productivity and profitability within subsystems so that simulations can be made of other sub-systems based on these relationships. More case studies need to be done to gain a more precise understanding of what type of productivity improvements will achieve the greatest increase in profitability. Also, the case studies are needed to further validate links and interdependencies in the spread sheet model.

\section{References}

Almström, P., Kinnander, A., 2011. The Productivity Potential Assessment method: assessing and benchmarking the improvement potential in manufacturing systems at shop-floor level. International Journal of Productivity and Performance Management, Vol. 60, No. 7, Accepted for publication.

Alsyouf, I., 2007. The role of maintenance in improving companies' productivity and profitability. International Journal of Production Economics, Vol. 105, No. 1, pp. 70-78.

Ayvaz, E., and Pehlivanli, D., 2011. The Use of Time Driven Activity Based Costing and Analytic Hierarchy Process Method in the Balanced Scorecard Implementation. International Journal of Business and Management, Vol. 6, No. 3, pp. 146-158.

Bernolak, I., 1997. Effective measurement and successful elements of company productivity: The basis of competitiveness and world prosperity. Int. J. Production Economics, Vol. 52, pp. 203-213.

Bicheno, J., 2004. The new Lean Toolbox, PICSIE Books, Bucingham

Boyd, L.H., Cox, J.F., 2002. Optimal decision making using cost accounting information. Int. J. Prod. Res., Vol. 40, No. 8, pp. 1879-1898.

Chen, Y., Chong, P.P., Tong, Y., 1993. Theoretical foundation of the 80/20 rule. Scientometrics, Vol. 28, No. 2, pp. 183-204.

Chougule, R. G., Ravi, B., 2006. Casting cost estimation in an integrated product and process design environment. International Journal of Computer Integrated Manufacturing, Vol. 19, No. 7, pp.676-688. 
Dettmer, W. H., 1997. Goldtratt's Theory of Constraints: A Systems Approach to Continuous Improvements, Wisconsin: Quality Press.

Flores, B.E., Olson, D.L., Dorai, V.K., 1992. Management of multicriteria inventory classification. Mathl. Comput. Modelling, Vol. 16, No. 12, pp. 71-82.

Flores, B.E., Whybark, C.D., 1986. Multiple Criteria ABC Analysis. International Journal of Operations and Production Management, Vol. 6, No. 3, pp. 38-46.

Geert, J.M., Nijssen, E.J., 2004. Performance effects of using the balanced scorecard: a note on the dutch experience. Long Range Planning, Vol. 37, pp. 335-349.

Hundal, M. S., 1997. Product Costing: A Comparison of Conventional and Activitybased Costing Methods. Journal of Engineering Design, Vol. 8, No. 1, pp. 91103.

IMD, International MTM Directorate, 2004. SAM - Sequential Activity - and Methods Analysis - System description.

Jensen, M.C., 1986. Agency costs of free cash flow, corporate finance and takeovers. American Economic Review, Vol. 76, No. 2, pp. 323-329.

Jinks, S., Scanlan, J., Reed, P., Wiseall, S., 2010. Utilising dynamic factory simulation to improve unit cost estimation and aid design decisions. In Proceeding of the 2010 Winter Simulation Conference.

Kaplan, R.S., Anderson, S.R., 2007. Time-Driven Activity-Based Costing. Harvard Business School Publishing Corporation.

Kaplan, R.S, Norton, D.P., 2008. Mastering the management system. Harvard business review, January.

Kaplan, R.S, Norton, D.P., 1992. The balanced scorecard - Measures that drive performance. Harvard business review, January-February.

Low, J., Siesfeld, T., 1998. Measures that matter: Non-financial performance. Strategy and Leadership, March-April, pp. 24-38.

Muchiri, P., Pintelon, L., 2007. Performance measurement using overall equipment effectiveness (OEE): literature review and practical application discussion. International Journal of Production Research, Vol. 46, No. 13, pp. 35173535.

Nakajima, S., 1988. Introduction to TPM: Total Productive Maintenance. Productivity Press, Cambridge, MA.

Neely, A., 2005. The evolution of performance measurement research - Developments in the last decade and a research agenda for the next. International Journal of Operations and Production Management, Vol. 25, No. 12, pp. 1264-1277. 
Niazi, A., Dai, J. S., Balabani, S., Seneviratne, L., 2006. Product cost estimation: Technique classification and Methodology review. Journal of Manufacturing Science and Engineering, Vol. 128, pp. 563-575.

Niebel, B., Freivalds, A., 2004. Methods, standards, and work design, 11th ed. McGraw-Hill.

Ong, N.S., 1995). Manufacturing cost estimation for PCB assembly: An activitybased approach. Int. J. Production Economics, Vol. 38, pp. 159-172.

Özbayrak, M., Akgün, M., Türker, A.K., 2004. Activity-based cost estimation in a push/pull advanced manufacturing system. Int. J. Production Economics, Vol. 87, pp. 49-65.

Park, J., Simpson, T. W., 2005. Development of a production cost estimation framework to support product family design, International Journal of Production Research, Vol. 43, No. 4, pp. 731-772.

Pehrsson, A., 2000. Strategy competence: a key profitability driver. Strategic Change, Vol. 9, No. 2, pp. 89-102.

Raham, S. U,, 1998. Theory of Constraints: a review of the philosophy and its applications. International Journal of Operations and Production Management, Vol. 18, No. 4, pp. 336-355.

Saito, S., 2001. Case Study: Reducing labor cost using industrial engineering techniques in Zandin, K. (ed), Maynard's Industrial Engineering Handbook.

Sakamoto, S., 2010. Beyond world-class productivity - Industrial engineering practice and theory, Springer-Verlag.

Sheu, S., Chen, M.H., Kovar, S., 2003. Integrating ABC and TOC for better manufacturing decision making. Integrated Manufacturing Systems, Vol. 14, No. 5, pp. 433-441.

Slack, N., Chambers, S., Johnston, R., 2010. Operations Management, $6^{\text {th }}$ ed., Prentice Hall.

Tangen, S., 2005. Demystifying productivity and performance. Int. J. of Productivity and Performance Management, Vol. 54, No. 1, pp. 34-46. 